Asia Pacific Journals

\title{
EXPERIMENTAL INVESTIGATION ON ACOUSTIC EMISSION FROM FUNCTIONALLY GRADED MATERIALS BASED POLYMER GEAR
}

\begin{tabular}{|c|c|}
\hline Akant Kumar Singh*, Siddhartha, Prashant Kumar Singh & Sanjay Yadav \\
Department of Mechanical Engineering & Department of Mechanical Engineering \\
National Institute of Technology, Hamirpur & I.T.S Engineering College, Greater Noida \\
Himachal Pradesh, India & Uttar Pradesh, India \\
"akant.nith@ @gmail.com & \\
\hline
\end{tabular}

\begin{abstract}
Polymer gears have positioned themselves as serious alternatives to traditional metal gears in a wide variety of applications. They have less weight, lower inertia and run much quieter than their metal counterparts. This paper investigates the leverage of fabrication techniques of polymer gear in the noise generation during operation. Polymer gears are fabricated by two different techniques i.e. conventional technique and horizontal centrifugal casting technique. Homogeneous gear is fabricated by conventional technique whereas horizontal centrifugal casting technique is used to fabricate functionally graded materials (FGMs) based thermoplastic spur gear. Polyamide materials filled with $15 \mathrm{wt} \%$ and $30 \mathrm{wt} \%$ glass fibers are used to fabricate homogeneous, and FGM gears. Unfilled Polyamide gear is also fabricated for comparative study. Gears are run at various speed and torque combinations. The range of the speed and torque is $500-1400 \mathrm{rpm}$ and $0.8-2.6 \mathrm{Nm}$, respectively. Sound power levels are recorded and analyzed for various running combinations of fabricated gears.
\end{abstract}

Keywords-FGM gear; Glass fiber; Polyamide; Polymer gear test rig; Acoustic emission

\section{INTRODUCTION}

Several plastics have been used successfully in gearing applications. The use of plastics gears has prompted many studies in both the plastics and gear industries. Gears are mechanical elements that transmit power or angular motion by successively intermeshing teeth. The spur is the most common type in operations between two parallel shafts. Most other types can be considered adaptations of the spur gear and special calculations are usually required for each [1]. Noise generation in a gear transmission system depends upon many factors such as gear quality, the contact ratio of the gear pair, gear material resilience, and operating conditions. In a light duty application, if the noiseless operation is the main objective, then polymeric materials that have good damping characteristics are preferred [2]. Gear noise can be a particular problem in all types of machines either because of unpleasant audible noise or because of the effect noise has on the operating characteristics of the machine, e.g. noise generated in high-precision copying machines can lead to inaccuracies in the picture being copied [3]. Steel gears are normally run under lubricated conditions and hence experience low friction, whereas the coefficient of friction of unlubricated plastics gears can be very high, as much as 0.8 [4]. This leads to high friction forces at the point of mesh and, as the friction force changes direction during the meshing cycle, this is an additional cause of noise in plastics gears. The problem is complicated by the high temperatures caused by friction and consequent changes in material properties, such as the elastic modulus, which decreases with temperature and hence alters the stiffness of the teeth thus changing the kinematic behavior of the gear teeth [5].

Polyamide (PA) gears running against steel have been investigated, and the noise was measured against running time where considerable wear had occurred on the PA gear [6]. The main conclusion of this work was that noise did not correlate well with wear, with very little change in noise level over time, even when the wear became gross. Also observed was the higher initial noise level when the gears were new. Hoskins et al. [7] investigated the acoustic noise from polymer gears and found that the sound power level of POM is inversely proportional to speed, but proportional to load, whereas in the other materials tested, is proportional to both speed and load. Noise and transmission efficiency under deformation of tooth form of nylon gear is investigated by Tsukamoto et al. [8]. It was observed that the noise of nylon gears is lower than the noise of steel gears because the sound pressure level is low when the frequency band is about 1.3 $\mathrm{kHz}$ and over. When the tooth profile of nylon gears changed in the running, the frequency characteristics of noise did not change clearly. However, the all sound pressure level changes in the first stage of running time up to $6 \times 10^{5}$ or $1.5 \times 10^{6}$ rotations. Dearn and Walton [9] studied the acoustic emission from polymeric gear and found that noise level was virtually independent of torque but much more dependent on speed.

Al-Qrimli et al. [10] concluded in their review article that FGMs should be used to fabricate gears. By using FGMs in the gear structure promises better performances. Centrifugal casting technique has been used to fabricate thermosetting (polymer matrix) base FGMs [11-16]. However to the best of author's knowledge, FGMs based thermoplastic gear has not been fabricated so far. The aim of this study is to develop FGMs based glass fiber reinforced polyamide gears and compare the acoustic emission of FGM gears with the homogeneous (Commercially available) gears.

\section{EXPERIMENTAL DETAILS}

\section{A. Gear Fabrication}

Glass fiber reinforced polyamide is used for the fabrication of FGM gear. FGM gears are prepared in proportions of 15 wt $\%$ and 30 wt $\%$ glass fiber reinforced polypropylene. Polyamide granules are preheated in the dryer at $90{ }^{0} \mathrm{C}$ for 3 


\section{Asia Pacific Journals}

hours before injection molding to remove the moisture content. The injection pressure of $7 \mathrm{MPa}$ and barrel temperatures of $220{ }^{\circ} \mathrm{C}, 230{ }^{\circ} \mathrm{C}, 240{ }^{\circ} \mathrm{C}$ at three zones are used for the gear fabrication. Punch is rotated for 2 minutes at 1800 rpm after filling the molten material into the punch cavity to prepare FGM gear. A pictorial view of the injection mold is shown in Fig. 1. polyamide matrix based homogeneous gears are also prepared for same weight percentage of glass fiber. Punch is kept stationary for homogeneous gear(s) fabrication. Unreinforced polyamide gear is also fabricated for comparative study. Unfilled and glass fiber filled polyamide is supplied by High Polymers, New Delhi, India. The manufactured gear specification is shown in Table 1 . A $16 \mathrm{~mm}$ bore diameter and key was formed in molded spur gears by a milling operation. Fabricated gears are shown in Fig. 2.

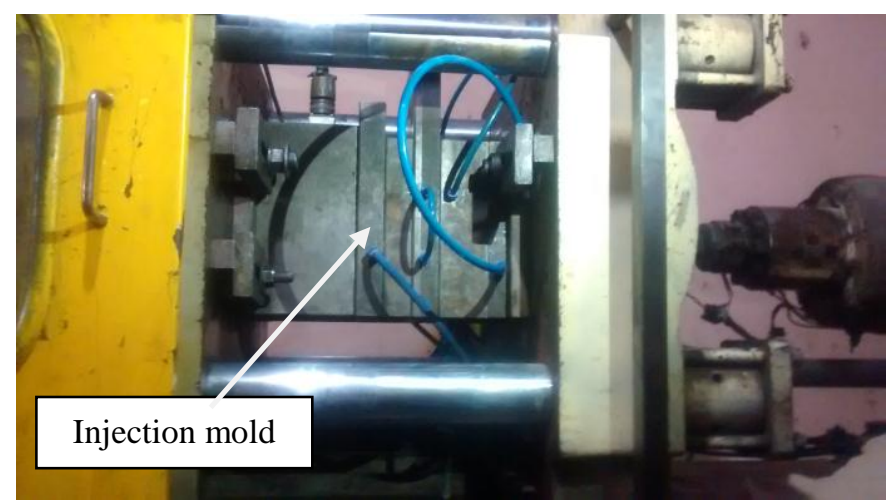

Fig. 1. Pictorial view of the injection mold

TABLE I. Specification of Thermoplastic Gears

\begin{tabular}{|l|c|}
\hline \multicolumn{1}{|c|}{ Material } & $\begin{array}{l}\text { i. Unfilled Polyamide } \\
\text { ii. 15 wt.\% glass fiber filled } \\
\text { Polyamide }\end{array}$ \\
& $\begin{array}{l}\text { iii. 30 wt.\% glass fiber filled } \\
\text { Polyamide }\end{array}$ \\
\hline Manufacturing method & \multicolumn{1}{|c|}{ Injection molded } \\
\hline $\begin{array}{l}\text { Pitch circle diameter } \\
\text { (mm) }\end{array}$ & 40 \\
\hline Pressure angle (deg.) & 20 \\
\hline Number of teeth & 20 \\
\hline Module (mm) & 2 \\
\hline Face width (mm) & 8 \\
\hline
\end{tabular}

\section{B. Polymer Gear Test Rig}

Gear tests are conducted using the power absorption type gear test rig. The polymer based test gear is driven using an $\mathrm{AC}$ motor to enable gear tests to be made at different speeds. An in-line torque transducer is connected to the motor shaft to measure the torque transmitted by the test gear.

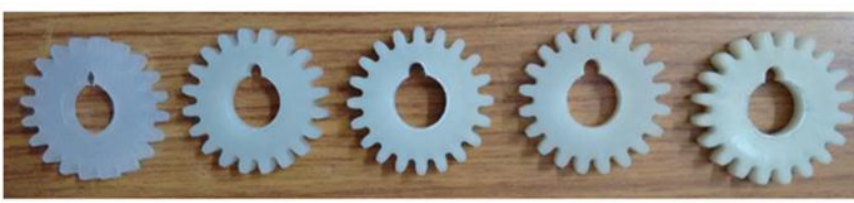

(a)

(b)

(c)

(d)

(e)

Fig. 2. Pictorial view of fabricated samples: (a) Unfilled polypropylene gear; (b) FGM gear filled with 15 wt.\% glass fiber; (c) FGM gear filled with 30 wt.\% glass fiber; (d) Homogeneous gear filled with 15 wt.\% glass fiber; (e) Homogeneous gear filled with $30 \mathrm{wt} \%$ glass fiber

The mating standard steel gear meshes with test gear to be rotated by it, but steel gear shaft is coupled to a dc motor to apply load. The principle to conduct the test is by rotating the test gear mating with standard steel gear at a specified speed and torque value for fixed number of cycles. The noise generated due to the meshing of gears is captured by the acoustic sensor. The acoustic sensor is positioned near the mating portion of gears. The vibration experienced by gear shaft while rotation is measured by an accelerometer mounted on plumber block. The arrangement of acoustic sensor and accelerometer in polymer gear test rig is shown in Fig. 3.

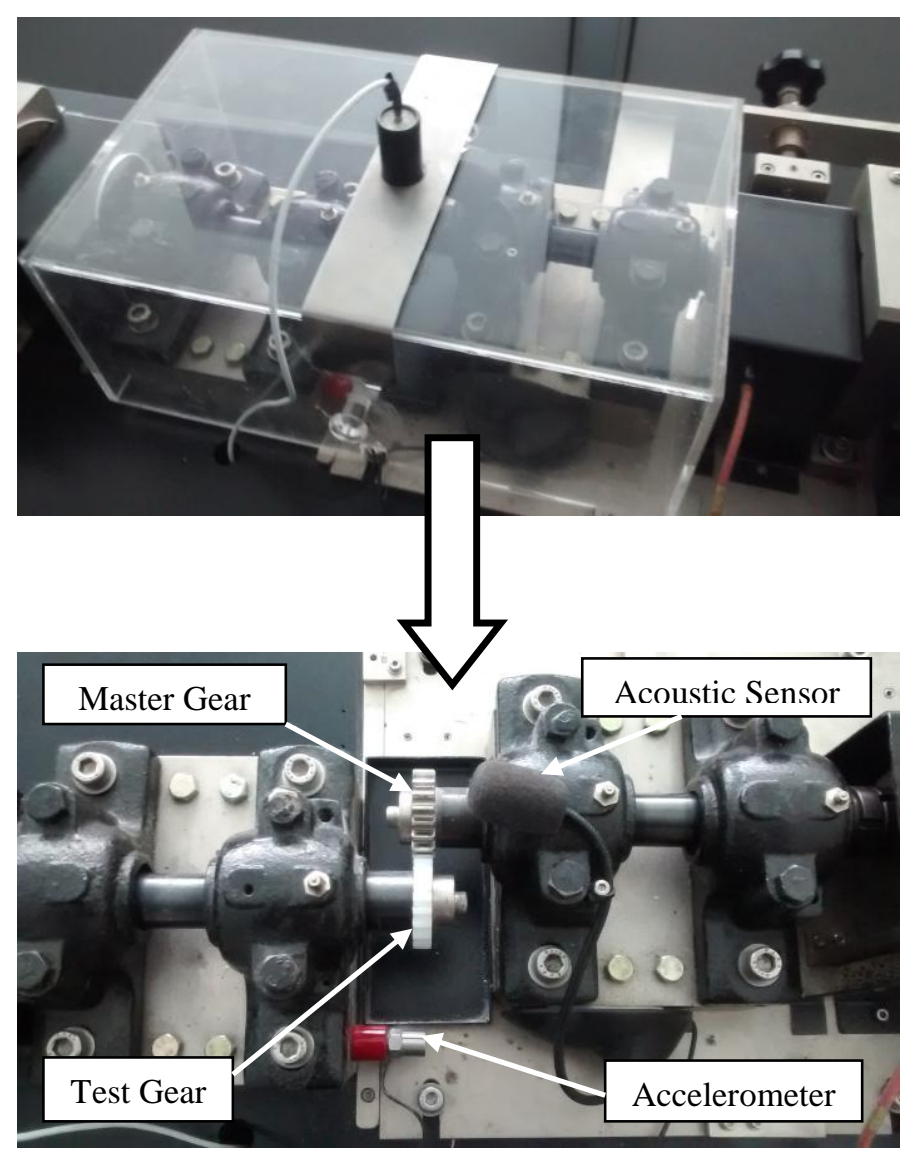

Fig. 3. The arrangement of acoustic sensor and accelerometer in polymer gear test rig. 


\section{Asia Pacific Journals}

\section{RESULT AND DISCUSSION}

Gears during service experience dynamic loads and the magnitude of dynamic loads depend on the quality of the gears, running speed, transmitting torque and gear material [17]. The noise and vibrational level of the gear depend on the dynamic loads. Fig. 4 and Fig. 5 shows the measured sound pressure near the gear mesh region (Fig. 3) during performance testing for 0.2 million cycles at different loading conditions. It is observed from Fig. 1 that noise generation from the gears is increased with increase in the speed. Unreinforced gear emits minimum whereas $30 \mathrm{wt} \%$ glass fiber reinforced homogeneous gear emits maximum noise at each speed. FGM gears produce minimum noise as compared to the homogeneous gears for both (15 and 30) weight percentage of fiber loading. Unreinforced polyamide gear emits minimum noise due to the high damping characteristics of unreinforced material [2]. FGMs have high damping factor as compared to homogeneous composites causes less noise generation in FGM gears [18]. It is clear from Fig. 4(a) and Fig. 4(b) that noise emission from the gears is marginally increased at each speed with substantial increment in torque.

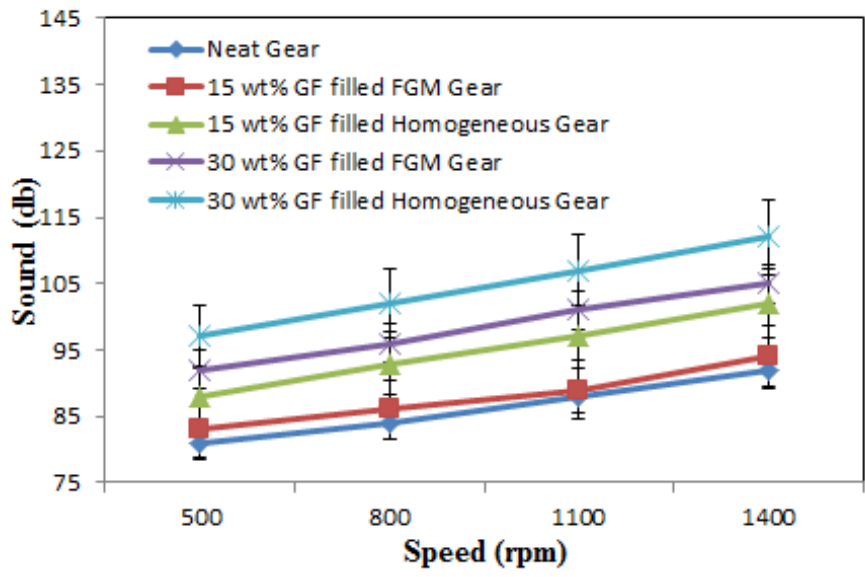

Fig. 4(a) Acoustic emission from the gears at Torque $=0.8 \mathrm{Nm}$ after $2 \times 10^{5}$ cycle

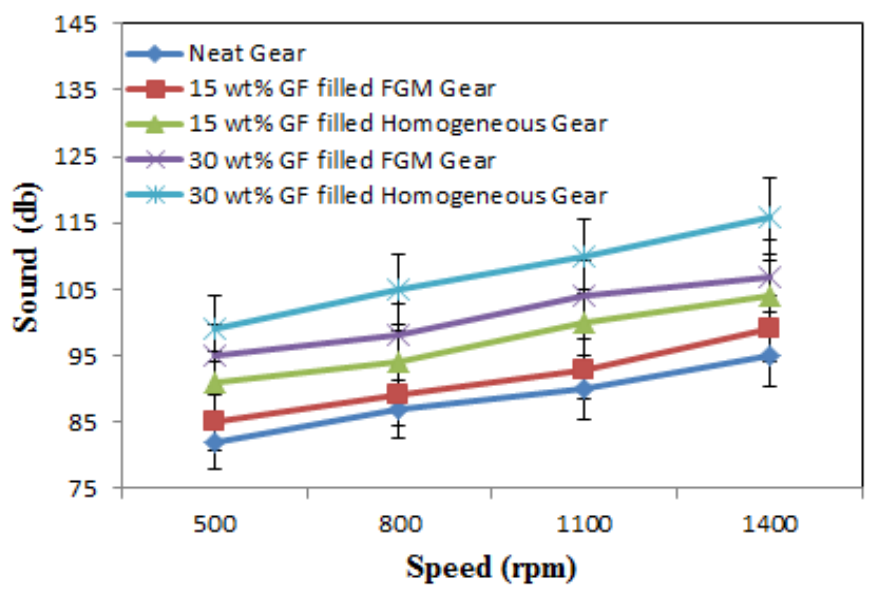

Fig. 4(b) Acoustic emission from the gears at Torque $=2.6 \mathrm{Nm}$ after $2 \times 10^{5}$ cycle
Noise increases with speed, probably due to the increase in tooth collision. For constant speed, noise emission from the gears is not much effected with increment in the torque. This phenomenon is observed for low (500 rpm) as well as for high speed (1400 rpm) as shown Fig. 5(a) and Fig. 5(b).

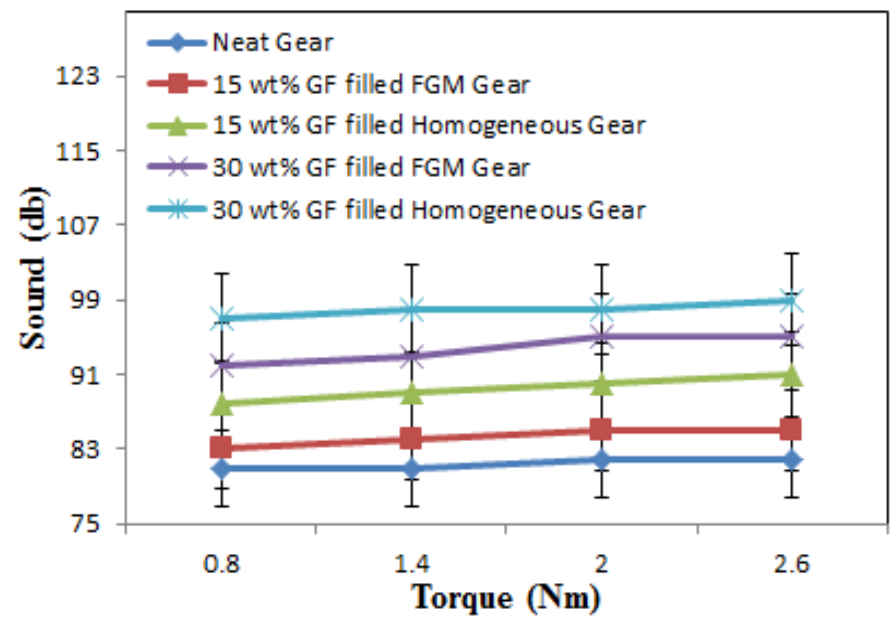

Fig. 5(a) Acoustic emission from the gears at Speed $=500 \mathrm{rpm}$ after $2 \times 10^{5}$ cycle

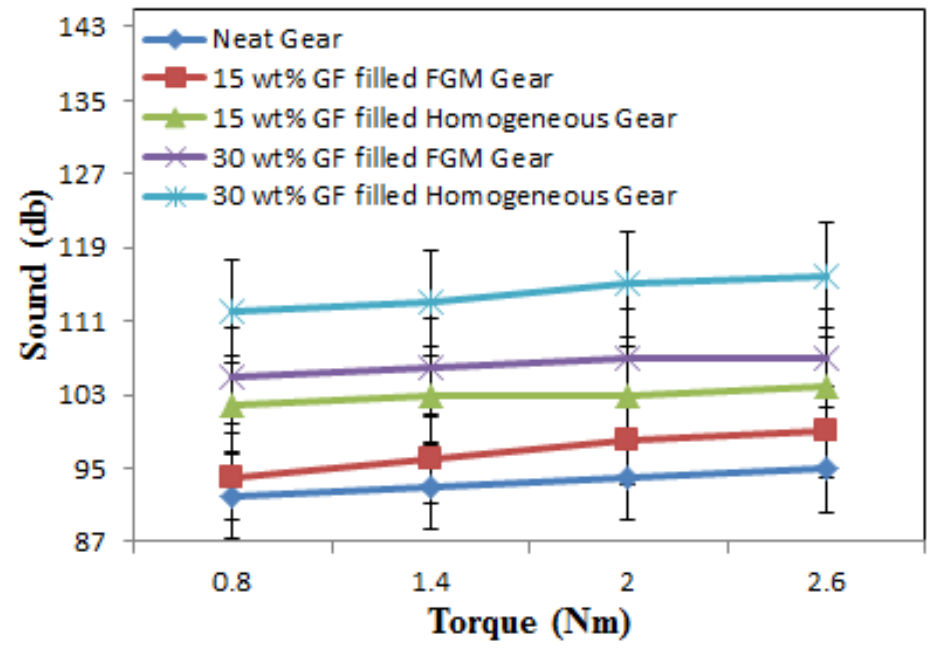

Fig. 5(b) Acoustic emission from the gears at Speed $=1400 \mathrm{rpm}$ after $2 \times 10^{5}$ cycle

It is observed from Fig. 5(a) and Fig. 5(b) that noise generation from the gears is high for high speed at each torque. Noise emission does not increase sufficiently with the increase in torque for constant speed, a result that may not be expected. There may be a probable reason for this. For plastic the coefficient of friction decreases with load, thereby reducing the friction forces acting between the meshing teeth [9]. Noise emission is increased at the initial stage of operation, but it is stabilized with the increment in the number of cycles as shown in Fig. 6. It is observed from Fig. 6 that noise emission from the gear is almost constant except $30 \mathrm{wt} \%$ glass fiber filled homogeneous gear. The amount of fiber is 


\section{Asia Pacific Journals}

quite high is $30 \mathrm{wt} \%$ glass fiber filled homogeneous gear and fibers are randomly oriented in the homogeneous gear teeth.

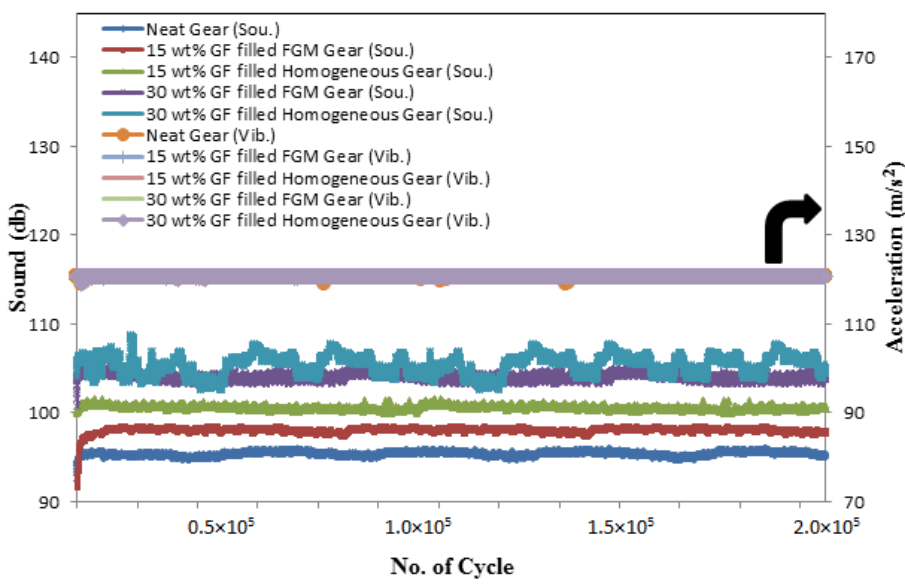

Fig. 6 Acoustic emission from the gears with increase in Number of cycle $($ Speed $=1000 \mathrm{rpm}$, Torque $=1.7 \mathrm{Nm})$

An array of randomly oriented fibers exposed on the gear teeth during operation causes unexpected noise pattern. Vibration in the shaft may increase the noise, but there is no vibration in the driven shaft during the experimentation of all type of gears. Fig 6 authenticates the statement where a constant straight line of acceleration is observed on the number of cycle for each type of gear. Noise emission is (218) $\%$ high in glass fiber reinforced gears as compared to unreinforced gear. Homogeneous gears produce (4-7) \% more noise as compared to FGM gears.

\section{CONCLUSIONS}

1. FGMs based glass fiber reinforced polyamide gears are fabricated successfully.

2. Noise emission from FGMs gear, homogeneous gear, and unreinforced polyamide gear is investigated.

3. Noise emission from the gears is increased with increase in the speed. Homogeneous gear emits more noise as compared to FGMs gear. Unreinforced gear produces minimum noise among all the fabricated gear.

4. Torque does not affect much to the noise emission from the gears. Noise emission from the gears is marginally increased with increase in the torque.

5. Noise emission is (2-18)\% higher in glass fiber reinforced gears as compared to unreinforced gear. Homogeneous gears produce (4-7)\% more noise as compared to FGM gears.

\section{REFERENCES}

[1] Adams, C.E., 1986. Plastic gearing: Selection and application, New York: Marcel Dekker, 1986

[2] S. Senthilvelan and R. Gnanamoorthy, "Damping characteristics of unreinforced, glass and carbon fiber reinforced nylon 6/6 spur gears,' Polym. Test., vol. 25, pp. 56-62, 2006.

[3] P.K. Meuleman, D. Walton, K.D. Dearn, D.J. Weale, and I. Driessen, "Minimization of transmission errors in highly loaded plastic gear trains," Proc I Mech Eng C, vol. 221, pp. 2041-983, 2008.

[4] C.J. Hooke, S.N. Kukureka, P. Liao, M. Rao, and Y.K. Chen, "The friction and wear of polymers in non-conformal contacts," Wear, vol. 200, pp. 83-94, 1996.

[5] M. Karimpour, k.d. Dearn, and D. Walton, "A kinematic analysis of meshing polymer gear teeth,” Proc I Mech Eng L, vol. 224, pp. 14644207, 2010

[6] R.E. Smith, "The relationship of measured gear noise to measured gear transmissions errors,” AGMA Fall Tech Meeting 87-FTM-6, 1987.

[7] T.J. Hoskins, K.D. Dearn, S.N. Kukureka, and D. Walton, “Acoustic noise from polymer gears - A tribological investigation," Mater. Des., vol. 32, pp. 3509-3515, 2011.

[8] N. Tsukamoto, T. Yano, and H. Sakai, "Noise and transmission efficiency under deformation of tooth form of nylon gear," Bull. JSME, vol. 25, pp. 1465-1473, 1982.

[9] K.D. Dearn and D. Walton, "Acoustic emission from polymeric gear," Proceeding of the world congress on engineering, vol. 2, 2009.

[10] H.F. Al-Qrimli, A.A. Oshkour, F.B. Ismail, and F.A. Mahdi, "Material design consideration for gear component using functional graded materials,” Int. J. Mates. Eng. Innov., vol. 6, pp. 243-256, 2015.

[11] Siddhartha, A. Patnaik, A. Satapathy, and A.D. Bhatt, "A study on modified mechanical and wear characteristics of epoxy-particulate filled homogenous composites and their functionally graded materials," J. Tribol. - T. ASME, vol. 133, pp. 011601-11, 2011.

[12] Siddhartha, A. Patnaik, and A.D. Bhatt, "Friction and wear analysis of a cement kiln dust reinforced epoxy-based functionally graded materials," J. Eng. Tribol., vol. 224, pp. 1103-1114, 2010.

[13] Siddhartha, A. Patnaik, and A.D. Bhatt, "Mechanical and dry sliding wear characterization of epoxy-TiO2 particulate filled functionally graded composites materials using Taguchi design of experiment," Mater. Des., vol. 32, pp. 615-627, 2011.

[14] Siddhartha, and A.K. Singh, "Mechanical and dry sliding wear characterization of short glass fiber reinforced polyester-based homogeneous and their functionally graded composite materials," P I Mech. Eng. L-J. Mater. Design Appl., vol. 229, pp. 274-298, 2015.

[15] Siddhartha, A.K. Singh, and S. Yadav, "Exploring the Possibility of Utilization of Red Mud Epoxy Based Functionally Graded Materials as Wear-Resistant Materials Using Taguchi Design of Experiment," Adv. polym. Tech., DOI 10.1002/adv.21567, 2015.

[16] A.K. Singh, Siddhartha, S. Yadav, and P.K. Singh, "Repercussion of Manufacturing Techniques on Mechanical and Wear Peculiarity of ZnO Particulate-Filled Polyester Composites," Polym. Composite, DOI 10.1002/pc.23982, 2016.

[17] G.M. Maitra, Handbook of Gear Design, Tata McGraw-Hill Pub. Ltd., New Delhi, 2003.

[18] B. Gangil, A. Patnaik, A. Kumar, and M. Kumar, "Investigations on mechanical and sliding wear behaviour of short fibre-reinforced vinyl ester-based homogenous and their functionally graded composites," P I Mech. Eng. L-J. Mater. Design Appl. Vol. 226, pp. 300-315, 2012. 